\title{
A ARTE NO CONTEXTO DA INFORMAÇÃO
}

\author{
ART IN BACKGROUND INFORMATION
}

Genesco Alves de Sousa ${ }^{1}$

Resumo: O presente ensaio propõe algumas reflexões sobre a arte produzida no contexto da Sociedade da Informação, destacando a relevância do conceito de informação tanto para a elaboração como para a interpretação de proposições artísticas articuladas em torno da relação entre arte e política. Para tanto, procede-se a uma análise de casos particulares, identificando aspectos que surgem, à luz dos avanços da tecnologia digital, como uma possível resposta às questões do esvaziamento político da arte contemporânea.

Palavras-chaves: Arte. Informação. Política. Tecnologia.

Abstract: This paper proposes some reflections about the art produced in background Information Society, highlighting the value of the concept of information for the preparation and interpretation of political art proposals. For this, analyze specific cases, in order to identify answers for the emptying of the political issues of contemporary art, under light the new digital technology.

Keywords: Art. Information. Policy. Technology.

\section{INTRODUÇÃO}

O objetivo deste artigo é refletir sobre os impactos diretos e indiretos do uso de tecnologias digitais na produção artística recente, utilizando conceitos e referenciais teóricos da crítica da arte contemporânea, assim como as contribuições dos próprios artistas em relação às

\footnotetext{
${ }^{1}$ Integrante da equipe de formação, experimentação e criação artística dos Centros de Convivência, Cultura e Saúde Mental de Belo Horizonte (SMSPBH). Mestre em Letras pela Universidade Estadual de Santa Cruz (UESC), Especialista em Educação e Relações Étnico-Raciais (UESC), Artista plástico, Graduado pela Escola Guignard/ Universidade do Estado de Minas Gerais (UEMG). E-mail: genescoa@gmail.com.
} 
suas práticas. Na atualidade, a relação entre arte e tecnologia sugere uma mudança de foco sobre a questão dos objetos culturais, evidenciada principalmente, conforme argumentou Bourriaud (2009:18), pelo fato de que "as obras já não perseguem a meta de formar realidades imaginárias e utópicas, mas procuram constituir modos de existência ou modelos de ação dentro da realidade existente". Trata-se, portanto, de uma relação que envolve alterações da noção de realidade e da natureza das proposições artísticas em geral. Mas, afinal, em que medida a tecnologia digital contribui para estas alterações? Qual a especificidade de sua incidência no âmbito da arte?

O advento de novas tecnologias e a sua apropriação através da arte são problemas constantes de investigação tanto para o crítico e o teórico da arte como para o artista, em seu processo criativo. $\mathrm{O}$ que a descoberta da perspectiva matemática significou para o Renascimento? Quais as consequências do processo fotográfico para a cultura modernista? Estes questionamentos ultrapassam os limites da investigação artística, transformando-se em referências para refletir sobre as mudanças de comportamento em diferentes contextos culturais. São passíveis, portanto, de serem reformulados à luz de problemas atuais.

Nessa linha encontram-se as contribuições de autores como Vilém Flusser (1985), Andre Rouillé (2009) e Nicolas Bourriaud (2009), tomando como ponto de partida os desafios e as possibilidades que o surgimento das imagens técnicas e o uso de tecnologias digitais trouxeram para a produção, a análise e a interpretação dos objetos culturais. Conforme advertiu Flusser (2013:31), se "antes, o objetivo era formalizar o mundo existente; hoje, o objetivo é realizar as formas projetadas para criar mundos alternativos".

A partir da ênfase nas relações intersubjetivas, supõe-se que a reflexão proposta possa contribuir, ainda que parcialmente, para discutir sobre a natureza e os desdobramentos das transformações ocorridas. Para tanto, esse ensaio apresenta inicialmente algumas questões teóricas centrais que atravessam a produção e a interpretação artística no contexto da Sociedade da Informação. Em seguida analisa-se, à luz dos desafios e possibilidades citados, determinadas propostas artísticas em que os efeitos da convergência entre arte e informação são facilmente identificados, inclusive como possíveis respostas à questão do esvaziamento político da arte contemporânea. 
Pontos de Interrogação, v. 4, n. 1, jan./jun. 2014

Revista do Programa de Pós-Graduação em Crítica Cultural

Universidade do Estado da Bahia (UNEB), Campus II - Alagoinhas - BA

\section{TUDO É INFORMAÇÃO. INFORMAÇÃO É TUDO!}

Tanto para os entusiastas como para os críticos, não resta dúvida de que fazemos parte de uma nova sociedade onde a informação desempenha um papel fundamental. Compartilhamos avanços e retrocessos que alimentam os debates, seguindo orientações distintas que incluem desde a visão idílica da democratização digital, a crença no determinismo tecnológico e até mesmo as suspeitas e as ameaças de novos modelos de sujeição, mas sem quaisquer dúvidas de algo novo está acontecendo.

Frank Webster (2006:9) argumenta que é possível conceber esta nova sociedade a partir de cinco definições distintas, identificando o que há de novo através dos critérios tecnológico, econômico, profissional, espacial e cultural. Para o autor ${ }^{2}$ :

Esses elementos não necessitam encontrar-se isolados dos demais, embora os teóricos salientem um ou outro elemento na apresentação dos seus cenários específicos. No entanto, o que é compartilhado por estas definições é a convicção de que as mudanças quantitativas de informação estão concretizando um novo tipo de sistema social, a sociedade da informação (2002:9).

O que mais impressiona no contexto da Sociedade da Informação é que a teorização sobre as nossas experiências assume uma configuração rizomática, abrangendo um espectro muito amplo de fenômenos diante do qual recomenda-se usar o bom senso. Se, por um lado, não há como negar que mudanças radicais estão estão acontecendo e que as suas consequências são relevantes, por outro lado, é necessário ser prudente ao analisá-las, levando em consideração a interdependência entre os fenômenos e as suas múltiplas dimensões (KUMAR, 1997:77).

Cabe ressaltar aqui que, em suas origens, o estudo científico da informação, categoria que define o novo sistema social, está relacionado com os processos de documentação e com os métodos de tratamento, organização, controle e acesso de dados. Além disso, a evolução desses processos e métodos não pode ser desvinculada do processo de desenvolvimento dos

\footnotetext{
2 "These need not be mutually exclusive, though theorists emphasise one or other factors in presenting their particular scenarios. However, what these defitions share is the conviction that quantitative changes in information are bringing into being a qualitatively new sort of social system, the information society" (WEBSTER, 2009: 8-9).
} 
computadores durante a Segunda Guerra Mundial e no período posterior. "O computador eletrônico em si surgiu”, segundo Krishan Kumar (2002:19) “principalmente para realizar cálculos balísticos e as análises que resultaram na bomba atômica”, através de estudos realizados em centros de pesquisa civil, com financiamento estatal e supervisão de órgãos públicos.

Ao mesmo tempo, as empresas multinacionais, cada vez mais internacionalizadas e enfrentando problemas semelhantes àqueles encontrados pelos militares, incrementaram seus processos de expansão absorvendo os sofisticados sistemas de tecnologia da informação. Sistemas que passaram a ser tão essenciais para o funcionamento dessas empresas quanto as suas fábricas e os seus operários. De acordo com Kumar (1997:20), essa estreita relação entre a revolução da informação e o surgimento de um complexo industrial-militar-científico pode não representar toda a história da Sociedade da Informação, mas corresponde no mínimo, à sua parte essencial.

Nesse aspecto, analisar o que se produz no contexto da Sociedade da Informação não é uma tarefa fácil. Além das dimensões sociais, políticas e econômicas que marcam a sua trajetória como objeto de estudo, deve-se considerar também que, do ponto de vista conceitual, a informação é uma categoria de difícil definição. Quase tudo que se produz atualmente pode ser considerado como informação ou como resultado do seu processamento, com significados que podem variar intensamente, dependendo da área do conhecimento em que estamos trabalhando.

Até mesmo no âmbito específico da Ciência da Informação, não há um consenso acerca da definição de informação. De acordo com Buckland (1991:352), a informação pode ser abordada simultaneamente como coisa, conhecimento e processo. Dados, textos, documentos e objetos informativos são tangíveis que podem ser medidos e quantificados. Como conhecimento, a informação é considerada intangível, deve ser comunicada e denota uma percepção a respeito de algo. Considerada na perspectiva do processo, sua função é informar, produzindo uma alteração daquela percepção que se tem de algo. Dito de outra maneira, sua função é transformar o conhecimento.

Na convergência destas definições, a noção de informação é ampliada e passa a ser utilizada quantitativa e qualitativamente para designar um universo: desde livros, roupas, bancos de dados, obras de arte, comportamentos, atos comunicativos, até mesmo viagens. Dessa ma- 
neira, a informação confunde os universos do tangível e do intangível, adquirindo o estatuto de uma entidade flutuante que pode materializar-se em suportes distintos, cujos valores são variáveis.

Tal confusão põe em marcha aquilo que Flusser (2013:56) denominou "transvaloração": o deslocamento do nosso foco de interesses das coisas para a informação, cuja valorização altera significativamente as relações de poder que envolvem a noção de propriedade.

Essa definição, aliás, é apropriada para o novo imperialismo: a humanidade é dominada por grupos que dispõem de informações privilegiadas, como por exemplo a construção de usinas hidrelétricas e armas atômicas, de automóveis e aeronaves, de engenharia genética e sistemas informáticos de gerenciamento. Esses grupos vendem as informações por preços altíssimos a uma humanidade subjugada (2013:56).

Com o mesmo argumento, em um texto anterior, Flusser (1985:27) propõe que o valor de uma fotografia é desprezível ponto de vista do objeto e o seu verdadeiro valor é determinado pela informação transmitida. Definida como uma imagem técnica primordial, a fotografia, além de configura a base das demais mídias contemporâneas, evidencia e torna palpável a questão dos valores do novos sistema social: Não se trata mais de possuir objetos, mas de dispor e controlar as informações.

Como resultado do aproveitamento e da aplicação de conceitos científicos, a imagem técnica enfatiza, ainda de acordo com a proposta flussseriana (1985:16), a relevância de questões relacionadas com a interface e com o programa. Diferente do sistema das imagens manuais, como a pintura, o sistema das imagens técnicas conta com a participação decisiva de uma interface programada tecnicamente, o aparelho fotográfico, cujo programa reflete as intenções de uma indústria fotográfica que, por sua vez, reflete as intenções de um contexto econômico, social, político e cultural.

\section{AS IMAGENS TÉCNICAS E ARTE}

Pode-se argumentar que as interfaces e os programas sempre existiram e que as ferramentas tecnológicas determinaram a produção dos artefatos e das informações em diferentes contextos culturais. Como interpretar a materialização do conceito universal de beleza sem 
considerar a instrumentalização das noções de ordem, equilíbrio, harmonia e proporção? Como entender que a experiência sensível da realidade pode ser isolada do plano dos conceitos e que os modos de visão possíveis pode ser reduzidos à teoria sem considerar a normatização radical promovida pelas leis a perspectiva matemática?

Em síntese, a questão da interface nas imagens técnicas pressupõe uma reflexão sobre a relação entre a ficção e a realidade. Técnicas e conhecimentos científicos foram utilizados no Ocidente, até meados do século XIX, para criar ilusões. A realidade visível duplicada na ficção da imagem, cujo propósito de fidelidade foi problematizado e superado pelas imagens técnicas. Com o advento da fotografia, a realidade não seria mais vista da mesma maneira e isso causou uma péssima reputação de toda a representação objetiva, pelo menos que se refere à arte (BELTING, 2006: 210).

A função social do artista, que até meados do século XVIII, estava relacionada com a questão da representação da realidade, em termos de aproximação e afastamento da mesma, foi deslocada para a questão da documentação, provocando debates sobre a ontologia da arte e contribuindo para intensificar experiências que resultaram em novas proposições artísticas.

Não é objetivo desse trabalho retomar a polêmica sobre a natureza e o valor da fotografia como arte, mas convém relembrar que a mudança do valor de culto para o valor de exposição, conforme proposto por Walter Benjamin em A obra de arte na era da sua reprodutibilidade técnica (1936), provocou uma reviralvolta que, para além das questões técnicas, radicalizou o modo como os artistas se relacionavam com a realidade e com os sistemas de representação, contribuindo para legitimar novas visibilidades.

O surgimento da fotografia na metade do século XIX trouxe, segundo André Rouillé (2009:52), uma resposta "à grave crise de confiança que aflige o valor documental das imagens manuais", confrontando o ideal da expressão criativa com a realidade do documento. Com a sucessão do paradigma artesal das imagens manuais pelo paradigma industrial das imagens técnicas, a transcendência foi ameaçada pela imanência, revelando que a hostilidade de alguns artistas em relação à fotografia era apenas uma parte de um confronto mais abrangente entre diferentes visões de mundo.

O valor documental da fotografia, fator que lhe garantiu maior credibilidade em relação às imagens manuais, estava vinculado à crença em sua automaticidade e sua objetividade. 
Durante muito tempo, esqueceu-se que entre o aparelho, a realidade e a imagem existia, e continua existindo, um sujeito. A especificidade da fotografia foi definida, inicialmente, por uma relação de contato imagem-coisa, como um documento que supostamente reproduzia exatamente as coisas do mundo (ROUILLÉ, 2009:69).

Desse modo, perfeitamente idêntica à coisa - tanto na aparência como na constituição e na substância de coisa -, a imagem torna-se indiscernível enquanto imagem e, em consequência, mesmo a noção de imagem e de imitação fica ameaçada. O que, ocasionalmente, justifica a recusa dos artistas em reconhecer o mínimo mérito artístico à fotogafia. De fato, a imitação supõe que a imagem duplica seu modelo, ao mesmo tempo que dele se distingue. Ela é menos a identidade do que a similaridade que, supostamente, faz a diferença. Essa diferença é acentuada pelas reduções e transformações, pela expressão e pela interpretação, por todas as defasagens espaciais, temporais, formais e materiais constitutivas da própria imagem. É de fato dessa diferença, supostamente ínfima e sempre infinita, designada pelo prefixo "re" da palavra "(re)presentação", que a imagem tira a sua força e a sua existência de imagem. Apesar de a diferença entre a coisa e sua imagem ser considerada infinitesimal, de ficar comprometida a distinção entre o original e a cópia, e a imitação anular-se através do ver. A imagem, então, é apenas o instrumento de um ver, e o dispositivo fotográfico, uma máquina de visão (2009:69).

Nessa perspectiva, os artistas da vanguarda modernista decidiram retomar a subjetividade que supostamente escapava ao registro mecânico do aparelho tentando se afastar da tradição e rejeitando as referências extraestéticas, originando uma acirrada concorrência por definições individualizadas do real. Diante da fragmentação e do fluxo de mudanças características da vida moderna, a busca por uma arte cada vez mais autônoma não impediu que alguns artistas aproveitassem as possibilidades oferecidas pela nova tecnologia, como no caso dos impressionistas, para colocar em prática um tipo de "pensamento fotográfico" (BOURRIAUD, 2009:94).

O movimento de afirmação da arte autônoma exigiu critérios de legitimação e diferenciação que explicitassem a especificidade das práticas artísticas. Em sua defesa do Expressionismo Abstrato, Clement Greenberg (2001:101), um dos mais persuasivos e influentes críticos norte-americanos do pós-guerra afirmou que a "essência do modernismo" encontrava-se no "uso de métodos característicos de uma disciplina para criticar a própria disciplina" não para "subvertê-la, mas para entrincheirá-la mais firmemente em sua área de competência". 
Debruçando sobre si mesmo, a arte modernista não conseguiu romper com a tradição em termos de perspectiva histórica, realizando simultaneamente uma separação e um prolongamento em relação à mesma. O Expressionismo Abstrato, nesse caso, representaria o último estágio de uma evolução interna rumo à sua autossuficiência. Assim, a identidade artística permanecia internamente dependende da participação em uma narrativa histórica universal, cujos limites definiam a importância, a autenticidade e o valor das propostas artísticas. O que estivesse além desses limites não fazia parte da história ou era tatatado como uma regressão.

Essa vertente foi confrontada por propostas estruturadas em torno de reflexões sobre a natureza da arte. A Arte Conceitual, por exemplo, contribuiu para uma revisão das noções de evolução, autonomia e criação. Refutando a postura teleológica defendida pelo formalismo de Greenberg, os artistas conceituais questionavam não apenas os critérios de definição, de exibição e de crítica da arte como também a sua relação com a estética.

É necessário separar a estética da arte porque a estética lida com opiniões sobre a percepção do mundo em geral. No passado, um dos dois destaques da função da arte era seu valor como decoração. Assim, qualquer ramo da filosofia que lidasse com a "beleza", e portanto com o "gosto", era inevitavelmente obrigado a discutir também a arte. A partir desse "hábito" surgiu a noção de que havia uma conexão conceitual entre a arte e a estética, o que não é verdade. Essa idéia, até recentemente nunca havia entrado em conflito de maneira drástica com as considerações artísticas, até recentemente, não só porque as características morfológicas da arte perpetuavam a continuidade desse erro, mas também porque as aparentes "funções" da arte (representar temas religiosos, retratar aristocratas, detalhar arquitetura etc) usavam a arte para encobrir a arte (KOSUTH, 1969:214).

Para os artistas conceituais, os objetos seriam conceitualmente irrelevantes para o julgamento estético e as suas proposições artísticas se confundiam com proposições analíticas. As tarefas de análise e intepretação, antes atribuídas aos críticos, deveriam ser deslocadas para a esfera do fazer artístico. Estabelece-se aqui uma analogia entre as questões da informação e da arte, através da relação entre o tangível e o intangível. Em outros termos, mas de modo semelhante, a Arte Conceitual põe em evidência as dimensões da arte enquanto coisa, conhecimento e processo.

Os artitas conceituais foram muito questionados, sobretudo, levando-se em conta que as suas proposições contribuiam para manter a experiência artística restrita à dimensão conceitual, definida como uma tautologia, ainda arte pela arte. Mesmo assim, é possível afirmar 
que a Arte Conceitual contribuiu para ampliar os horizontes da produção e da interpretação artística, deslocando o foco de interesse para além dos objetos e, consequentemente, facilitando a incorporação de referências extraestéticas.

Se, até então, o enquadramento da arte na história universal era tão importante quanto os próprios artistas e obras, já que este era o instrumento que os definia hieraquicamente. A partir do momento em que essa localização foi minada pelos questionamentos ontológicos da arte, abriram-se os caminhos para que as dimensões políticas, econômicas e sociais entrassem em cena de um modo distinto, principalmente através de novas clivagens articuladas em torno das questões de identidade, diferença, gênero, etnia e memória. O multiculturalismo do "outro" versus o monoculturalismo do mesmo.

\section{INFORMAÇÃO, ARTE E POLÍTICA}

A partir dessas novas clivagens e da articulação entre arte e política, alguns artistas estabeleceram outras conexões com a realidade. Não se trata mais de sonhar um futuro ideal, mas de realizar no e a partir do presente, vislumbrando respostas para a questão do esvaziamento e a nulidade política no contexto da Sociedade da Informação. De alguma maneira, procura-se superar a lacuna entre as realidades da arte e das relações sociais, repensando a própria concepção de arte e seus vínculos com a questão do desenvolvimento tecnológico, da ciência e da informação.

As obras aqui analisadas identificam-se com três vertentes artísticas distintas, configuradas a partir do uso de imagens técnicas e articuladas em torno da relação entre arte e política, seguindo a classificação proposta por André Rouillé (2009:389) como: a) arte crítica; b) arte feita politicamente; c) arte de produzir visibilidades. O quarto e último caso apresentado, no entanto, mesmo não se enquadrando em nenhuma das vertentes anteriores, recupera e aproveita algumas de suas premissas.

Na primeira vertente, identifica-se o artista alemão radicado em Nova York, Hans Haacke, cuja proposta tem o propósito de criticar artisticamente situações sociais e políticas particulares. Para tal, empreende ações que ultrapassam os limites do "complexo institucional". Em 1986, Hans Haacke reconstruiu a fachada de uma loja do grupo Cartier substituindo a 
vitrine original por uma fotografia de manifestantes negros. Os objetivos principais deste trabalho intitulado Le must de Rembrandt ${ }^{3}$ consistiam em expor e criticar a outra face do mundo das jóais e dos diamantes produzidos e comercializados pela Cartier, enfatizando as conexões entre a Fundação Cartier para a Artes Contemporânea ${ }^{4}$ e o truste sul-africano Rembrandt ${ }^{5}$, proprietário de minas de ouro e de platina na África do Sul, aliado de grupos extremistas do apartheid e conhecido por sua política de repressão violenta às greves.

Em Livre-Troca: diálogos entre ciência e arte (1995), publicação realizada em parceria com o sociólogo francês Pierre Bourdieu, Hans Haacke argumenta que esta proposta está relacionada com a ideia de "fachada cultural", em referência à apropriação da noção tradicional do mecenato pelas empresas através de estratégias de comunicação corporativa.

Invocando o nome de Mecenas, as empresas de hoje se dão uma aura de autruísmo. O termo americano de Sponsoring explica melhor que existe, na realidade, uma troca de bens, de bens financeiros da parte do patrocinador e de bens simbólicos da parte do patrocinado. A maioria dos homens de negócio é mais direta quando fala a seus pares. Alain-Dominique Perrin, presidente da Cartier, por exemplo, diz que ele gasta o dinheiro da Cartier visando metas que nada tem a ver com o amor à arte (1995:28).

Trata-se, portanto, de uma proposta de arte engajada que critica diretamente a função social da arte e suas relações institucionais, através do processamento e da socialização de informações sobre o universo corporativo e suas manobras políticas utilizando a arte. A intenção é oferecer respostas, mas apenas o contato com a obra e uma postura contemplativa diante da mesma não garantem a sua fruição nem que a mesma seja compreendia em sua totalidade, sendo necessário um mínimo de conhecimento ou até mesmo de aprofundamento em relação às informações que estão sendo processadas e apresentadas ao público.

\footnotetext{
3 A referência ao "Must de Rembrandt" tem relação com a ideia-símbolo das campanhas publicitárias desta empresa - "Les must de Cartier" (1995:44).

${ }^{4}$ A Cartier é um dos patrocinadores das artes plásticas na França. Em 1984, Alain-Dominique Perin, o presidente da Cartier, instalava a Fundação Cartier para a arte contemporânea em Jouy-en-Josas, às portas de Paris. A Fundação desde então montou um grande número de exposições, algumas diretamente relacionadas ao mundo dos produtos de luxo (1995:41)

${ }^{5}$ O grupo Rembrandt foi criado em 1940 por Anton Rupert. (...) Na África do Sul, Rembrandt está fortemente presente em setores como o das minas, da construção mecânica, dos bancos, dos seguros, dos serviços financeiros, dos produtos derivados do petróleo e da petroquímica, da exploração florestal e da filial de madeira, da impressão e da embalagem, do tabaco, de alimentação e de licores. (...) Um autorretrato de Rembrandt datado de 1634 serve de logotipo para o grupo Rembrandt (BOURDIEU, HAACKE, 1995:40-41)
} 


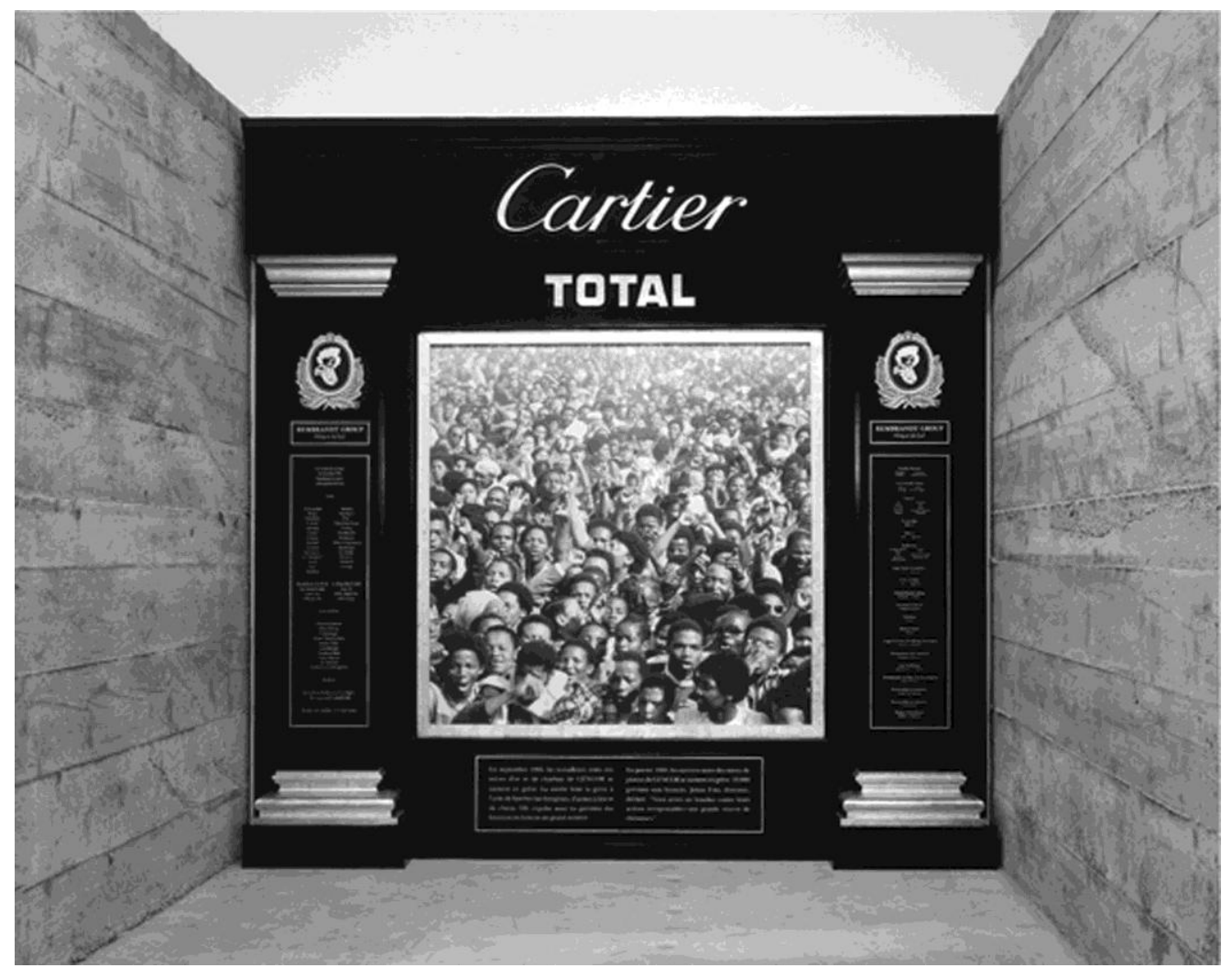

Imagem 1: Instalação Les Must Rembrandt (1986), de Hans Haacke. Fonte: BOURDIEU, Pierre, HAACKE, Hans (1995: 41).

Em relação à segunda vertente, Rouillé (2009:396) afirma que na arte feita politicamente também há um esforço para expandir-se além dos espaços institucionais das galerias, dos museus e dos catálogos de arte, tentando criar dispositivos para interferir na rotina diária. Este é o caso do artista norte-americano Dennis Adams que, em 1990, realizou um trabalho na cidade de Derry, na Irlanda do Norte, palco de um confronto ocorrido em 30 de janeiro de 1972, conhecido mundialmente como Domingo Sangrento (Bloody Sunday em inglês), envolvendo manifestantes civis, católicos e protestantes, e o exército britânico, que resultou na morte de 14 manifestantes católicos.

No bairro onde ocorreu o confronto, Adams instalou uma espécie de trave de futebol gaélico, esporte praticado por católicos, medindo dez metros de comprimento e sete metros de altura, substitindo as redes por grades de ferro. Na trave, o artista acrescentou uma montagem fotográfica que mostrava a demolição dos prédios que serviram de barricada durante o confronto. 
Em síntese, Siege (cerco em inglês) consiste em um proposta que remete não apenas aos mecanismos de defesa e vigilância e aos conflitos sociais particulares, mas também às questões da história e da memória coletiva através dos espaços urbanos. Se, por um lado, a pretensão é inventar outros procedimentos para problematizar a realidade sem criticá-la diretamente, como na primeira vertente, por outro lado, assim como no caso da proposta de Haacke, demanda um percurso em busca das informações que envolvem os conflitos religiosos na Irlanda do Norte.

No caso da terceira vertente, conforme analisa Rouillé (2009:402), os artistas não dispensam a colaboração do "complexo institucional" para produzir novas visibilidades e o seu objetivo principal "é tentar frustar o processo de representação". Em agosto de 1994, o artista chileno Alfred Jaar iniciou o Projeto Rwanda (1994-2000), realizando mais de três mil fotografias das vítimas do genocídio ocorrido em Ruanda, na África, no mesmo ano. Em seguida, Jaar decidiu não mostrar as imagens. Em 1995, o artista realizou a instalação Real Pictures (imagens reais em inglês), como parte do Projeto Rwanda, depositando provas fotográficas em caixas pretas hermeticamente fechadas. Em cima de cada caixa, o artista anotou uma descrição da imagem.

Ainda de acordo com Rouillé (2009:408-409), a radicalidade do Projeto Rwanda (1994-2000) é determinada por um gesto estético que inverte o modelo documental. A decisão de descrever as imagens das vítimas do genocídio ao invés de mostrá-las é um ato de resistência à compulsão de documentar os horrores da guerra da maneira como o fazem as agências de reportagem. "Em vez do culto da reprodução do real, toma lugar a aguda consciência de que o excesso de imagens satura o olhar, desvia a atenção e embaralha a consciência".

Para finalizar, no trabalho do artista brasileiro Eustáquio Neves é possível identificar algumas características principais que definem as demais vertentes, com destaque para o trabalho de pesquisa e documentação que envolve os processos criativos e o uso sistemático das imagens fotográficas. Na série Máscara de Punição (2002-2003), Eustáquio Neves utilizou um retrato fotográfico de identificação pessoal da própria mãe, realizando sobre o mesmo diversas intervenções físicas e químicas, entre as quais a sobreposição de uma imagem de uma máscara de metal utilizada para castigar escravos, recolhida durantre uma pesquisa realizada pelo artista no Museu do Escravo, no interior de Minas Gerais. 

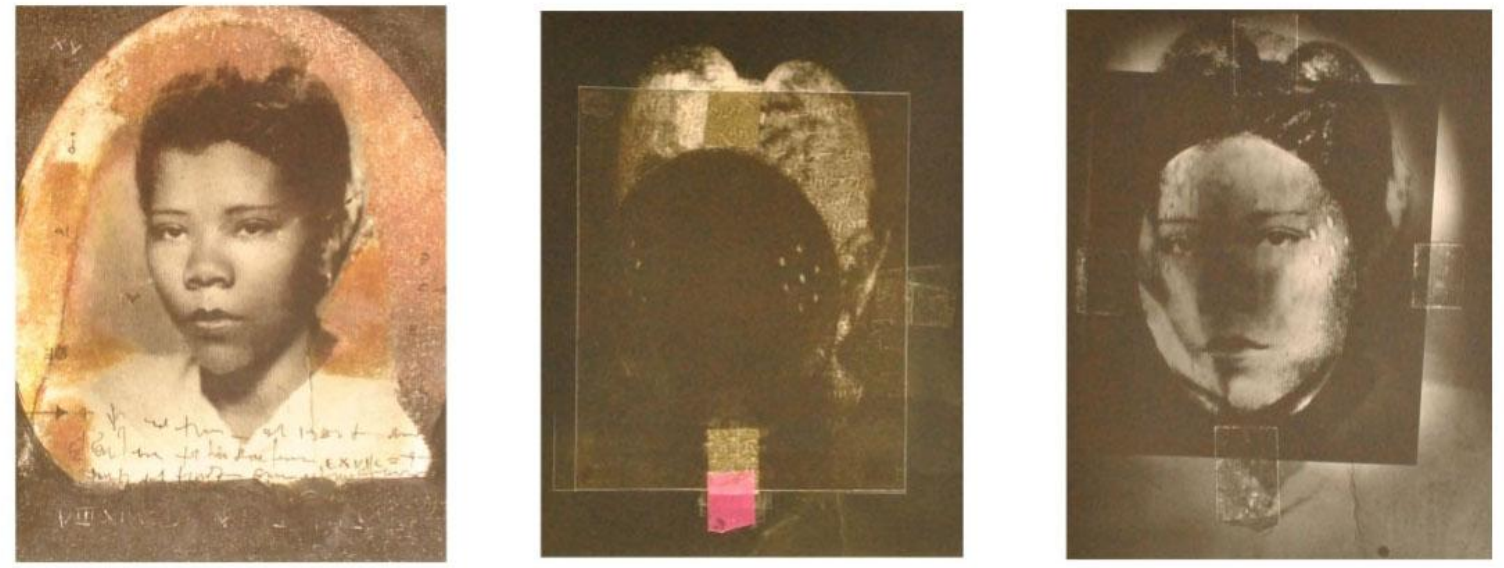

Imagem 2: Fotografias da série Máscara de Punição (2002-2003), de Eustáquio Neves. Fonte: Mostra Eustáquio Neves: exposição panorâmica, Museu de Arte da Pampulha, 2010/2011. Fotografia: Genesco Alves (2011).

Esta série fotográfica é composta por três imagens distintas que mostram o processo de fusão da máscara com o retrato de uma mulher negra. A primeira imagem mostra a figura da mulher com algumas inscrições, numa alusão direta às fotografias oitocentistas de escravos e ex-escravos que eram comercializadas como lembranças do Brasil no exterior. Na segunda imagem, mesmo com a sobreposição da máscara, ainda é possível ver a figura da mulher, enquanto que, na terceira imagem, essa figura se torna irreconhecível.

É óbvia a relação que se estabelece com a temática da escravidão brasileira e com a experiência vivenciada pelos escravos. Nessa perspectiva, o conjunto das imagens poderia ser interpretado como uma proposta de crítica social direta. Por outro lado, também é possível estabelecer uma aproximação, do ponto de vista formal, entre a primeira imagem e a estética fotográfica oitocentista correlacionando-as com as teorias evolucionistas que vigoraram naquele período e influenciaram a elaboração do projeto de identidade nacional no Brasil. De maneira análoga, a fusão da máscara com o documento de identificação pessoal, coloca em um mesmo nível de importância o objeto que subjuga e a informação que reflete a normatização social, problematizando a iconografia do negro brasileiro.

Além disso, é possível interpretar a série como um desafio a respeito da representação da identidade afrodescendente num país como o Brasil, considerando que a série reúne imagens referentes a diferentes períodos da história nacional. Uma das imagens mostra um sím- 
bolo da escravidão, no período em que o escravo foi tratado como um objeto. O retrato de identificação pessoal, por sua vez, revela um sujeito, aquele que alcançou a cidadania atravessando etapas que envolvem negação, conflitos, reconhecimento e afirmação. A terceira imagem, que funde as duas anteriores, sugere uma condição ambivalente, relacionada com a dificuldade de representar esse sujeito fora das usuais opções de enquadramento. Mais que uma releitura da opressão imperialista, a proposta aponta para a dificuldade de reconciliação da sociedade brasileira com o seu passado colonial, com a sua memória e a sua história. A máscara, nesse caso, serve tanto para encobrir como para mostrar, entre a negação e a afirmação, a indefinição aparece como um caminho mais coerente.

\section{CONSIDERAÇÕES FINAIS}

Até pouco tempo, permanecíamos em um terreno em que a verdade do real era encontrada no objeto tangível, acessível através da visão. Orientar-se nesse terreno, segundo Flusser (2013:52) significava diferenciar coisas naturais de coisas artificiais. Atualmente, nossos instrumentos de orientação foram alterados com o deslocamento do foco existencial para as informações. Passamos a habitar mundos distintos simultaneamente, inclusive o intangível, e a diferença entre ambos é o que nos fornece as referências e os argumentos para pensar nas novas produções culturais.

A maneira de entender tal diferença encontra-se em nossos próprios gestos e naquilo que somos capazes de realizar nesse universo intangível, em comparação com o que alcançamos no mundo dos fenômenos. No espaço das tecnologias digitais, a tendência é restituir as ilusões do espaço tradicional. Assim, restituimos a perspectiva espacial e a expectativa temporal onde as mesmas não existem e aceitamos algumas premissas que disfarçam a natureza hierárquica desse ambiente. Ilusões que estão ali, na maioria das vezes, para dar a impressão confortável de que não perdemos o contato com o real.

Tem-se a impressão de que estamos interagindo e acreditamos ingenuamente que somos os donos do jogo. Não podemos perder de vista que essa interatividade consiste em uma “uma mediação digital tecnicamente programada" (CAUQUELIN, 2008: 168) e no espaço da programação é necessário decidir politicamente qual o nosso papel: programadores, funcionários ou jogadores? Com relação à essa necessidade de tomar partido é que as propostas anali- 
sadas, através do aproveitamento da tecnologias digitais disponíveis, parecem indicar alguns caminhos.

\section{REFERÊNCIAS}

BOURDIEU, Pierre, HAACKE, Hans. Livre-Troca: diálogos entre ciência e arte. Tradução Paulo Cesar da Costa Gomes. Rio de Janeiro: Bertrand Brasil, 1995.

BOURRIAUD, Nicolas. Estética relacional. Tradução de Denise Bottmann. São Paulo: Martins Fontes, 2009.

BUCKLAND, M. K. Information as thing in: Journal of the American Society for Information Science, New York. V. 45, n. 5, p. 351-360, 1991.

CAUQUELIN, Anne. Freqüentar os incorporais: contribuições a uma teoria da arte contemporânea. Tradução de Marcos Marcionilo. São Paulo: Martins Fontes, 2008.

FLUSSER, Vilém. $O$ mundo codificado: por uma filosofia do design e da comunicação. Organizado por Rafael Cardoso. Tradução Raquel Abi-Sâmara. São Paulo: Cosac Naif, 2013.

KOSUTH, Joseph. Arte depois da filosofia in: FERREIRA, Glória e COTRIM, Cecília (orgs). Escritos de Artistas: anos 60/70. Tradução de Pedro Süssekind ...et al. Rio de Janeiro: Jorge Zahar Editor, 2006. p. 210-234.

GREENBERG, Clement. Pintura Modernista in: FERREIRA, Glória e COTRIM, Cecília (orgs). Clement Greenberg e o debate crítico. Rio de Janeiro: Jorge Zahar Editor, 2001. p. 101-110.

KUMAR, Krishan. Da socieade pós-industrial à pós-moderna: novas teorias sobre o mundo contemporâneo. Tradução Ruy Jungmann. Rio de Janeiro: Jorge Zahar Editor, 1997.

ROUANET, Sérgio Paulo. A verdade e a ilusão do pós-modernismo in: As razões do Iluminismo. São Paulo: Companhia das Letras, 1987. p. 229-277.

ROUILLÉ, Andre. A fotografia: entre documento e arte contemporânea.Tradução Constancia Egrejas São Paulo: Editora SENAC São Paulo, 2009.

WEBSTER, Frank. Theories of the Information Society. 3. ed. London: Routledge, 2006.

Recebido em: 20 de março de 2014.

Aceito em: 16 de abril de 2014. 